\title{
Luigi Rizzi
}

\section{Notes on cartography and further explanation}

\begin{abstract}
This article addresses one particular aspect of the cartographic enterprise, the cartographic study of the left periphery of the clause, the system of criteria, and the "syntacticisation" of scope-discourse semantics that rich and detailed syntactic maps make possible. I will compare this theoretical option with the conceivable alternative, the "pragmaticization" of a radically impoverished syntax, and will discuss some simple kinds of empirical evidence bearing on the choice between these alternative perspectives. I will then turn to the issue of whether the properties of the functional sequence (ordering, cooccurrence restrictions) are amenable to "further explanations" in terms of more basic principles constraining linguistic computations. I will argue that the search for deeper explanations is an integral part of the cartographic endeavour: it presupposes the establishment of reliable maps, and nourishes the pursuit of further cartographic questions. I will conclude by illustrating the issue of further explanation by comparing certain properties of topicalization in English and Italian, in particular the fact that DP topics are fundamentally unique in English, while they can be freely reiterated in Italian. This pattern can be plausibly traced back to intervention locality, once certain independent properties distinguishing Italian and English topicalization are taken into account.
\end{abstract}

Keywords: syntax, cartography, left periphery, criteria, locality

Luigi Rizzi: University of Siena, Italy and University of Geneva, Switzerland E-mail: luigi.rizzi@unisi.it

\section{Introduction}

In syntactic analyses of the late 1980's, the success of Pollock's (1989) Split Infl approach led to a quick proliferation of the functional elements assumed to constitute the spine of the clause. After the separation of agreement and tense, each further splitting ( $\mathrm{T}$ and Asp, etc.) gave rise to descriptively richer and more adequate analyses; at the same time the trend raised the question of where the splitting process would stop: what would be the atoms of syntactic computations? When and how could one confidently conclude that the atomic level was reached? 
One initial motivation of cartographic projects was the attempt to address these questions by changing the perspective. Rather than postulating functional elements as an ancillary assumption in the context of the analysis of other properties (locality, case-agreement, word order, ellipsis, etc.), one could directly focus on the functional structures of different zones of the clause, study their properties and draw maps as accurate as possible of the maximal expansion of such zones (Rizzi 1997, Cinque 1999). So, one could acknowledge that syntactic representations are rich and complex objects, and the study of this complexity could become an object of inquiry worth pursuing on its own: what functional elements can occur in a given zone? What are the co-occurrence and ordering restrictions? How can they be explained? The hope was that such detailed maps would on the one hand lead to the discovery of the ultimate constituents of syntax, thus building the "splitting” approach on solid foundations, and on the other hand the structural maps would enter into deeper explanations of linguistic phenomena, and possibly would be useful in applicative domains, as reliable maps often are. So, one could imagine that a detailed structural cartography would be of help for first and second language acquisition research, the study of pathologies, computational applications, and the like.

As cartographic analyses started, it became clear that certain simplicity assumptions offer optimal guidelines for this kind of endeavour. The main guideline is that heads and phrases are simple entities. A head (a functional head in particular) can be expected to be defined, in the ideal case, by a single morphosyntactic feature: complex conglomerates of features (e.g., a verb inflected for tense, mood and agreement) can arise as a consequence of movement, but are not syntactic atoms (a guideline that is fully exploited in "nanosyntax" studies: Starke 2009). Projections are simple, binary branching Specifier-headcomplement configurations: no multiple complements, no multiple specifiers, no special mechanisms for adjunction are assumed, much as in the antisymmetry approach (Kayne 1994). These are guidelines that have turned out to be particularly congenial to the cartographic endeavour, but clearly they do not simply reflect methodological decisions: they ultimately express empirical hypotheses on the nature and organisation of natural language syntax.

One aspect of the emerging picture is that natural languages privilege local simplicity of configurations and relations, accepting the price of an increased global complexity through the reiterated combination of simple atomic structures made possible by recursive Merge. An independent and complementary aspect of the "local simplicity" idea is that the functional lexicon is much richer than in traditional views. How rich? The determination of the size of the functional lexicon clearly is a crucial empirical issue for cartographic studies, one on which a fruitful interaction can be envisaged with typological studies on the possible tar- 
gets of grammaticalisation (Heine and Kuteva 2002, and Cinque \& Rizzi 2010, Kayne 2005, ch. 12, Roberts and Roussou 2003, Roberts 2012 for relevant discussion). In short, the emerging picture is one with numerous but extremely simple syntactic atoms, which combine through recursive Merge to give rise to very complex syntactic molecules. The cartographic endeavour aims at capturing this articulation, work out our Mendeleyev table, and map the complex molecular shapes that atomic constituents can be arranged into.

In this article I will address one particular aspect of this enterprise, focusing on the cartographic study of the left periphery of the clause. I will characterize the system of criteria, and the "syntacticisation" of scope-discourse semantics that rich and detailed syntactic maps make possible. I will then discuss this theoretical option in comparison with the conceivable opposite approach: the "pragmaticization" of a radically impoverished syntax, shifting much of the computational burden to post-syntactic components after the interface. This alternative will lead us to consider the properties of criterial particles and the cases of multiple complementizers occurring in distinct positions, or co-occurring in the same structure. I will then turn to the issue of whether the properties of the functional sequence (ordering, cooccurrence restrictions) are amenable to "further explanations" in terms of more basic principles constraining linguistic computations. I will argue that further explanations can and must be pursued, and that, if successfully achieved, they do not endanger the cartographic enterprise: on the contrary, any attempt at further explanations presupposes and integrates the exploration of cartographic maps. I will conclude by illustrating the issue of further explanation by comparing certain properties of topicalization in English and Italian, in particular the fact that DP topics are fundamentally unique in English, while they can be freely reiterated in Italian, a pattern which can be plausibly traced back to intervention locality, once certain independent distinctive properties between Italian and English topicalization are taken into account.

\section{The "syntacticisation" of scope-discourse semantics: The criteria}

Minimalist syntax has put much emphasis on the role of economy considerations in formal syntax: syntactic operations have a cost in terms of computational resources, and natural language syntax is designed in ways to minimize that cost in the expression of the intended meanings. One corollary of this view is that syntactic operations have well-defined functions in the expression of meaning (or to ensure well formedness at the interface with morphology, or with the sound 
system, functional motivations which will not be addressed here). There is a division of labor between external and internal Merge from this viewpoint. External Merge creates local configurations for the expression of semantic selectional properties, theta roles in the case of arguments. In a complementary manner, one core case of internal Merge, yielding $A^{\prime}$-chains, creates configurations for the expression of scope-discourse semantics: the assignment of a proper scope domain to operators, the creation of syntactic structures for discourse related articulations such as topic-comment, and focus-presupposition. Consider $\mathrm{A}^{\prime}$ constructions such as those involved in questions, topicalization and focalisation:

(1) a. Which book should you read < which book>?

b. This book, you should read <this book $>$ tomorrow

c. THIS BOOK you should read $<$ this book $>$ (, not that one)

In these cases the same syntactic constituent is interpreted as a thematic argument ("patient") of the verb read, and as the carrier of a certain scope-discourse function, as an interrogative operator, topic or focus. Natural languages in this case solve the problem of assigning the two kinds of interpretive properties by having the element occur twice, in positions dedicated to the two types of properties. The double occurrence is particularly clear under the copy theory of traces, adopted here (with the trace a silent copy expressed in (1) within angled brackets).

In what sense is a syntactic position "dedicated" to a particular interpretive property? In the case of argumental semantics and thematic roles, it is uncontroversially a matter of head-dependent relation: a verb assigns a certain thematic role to its dependents, complement and specifier (or, if one thinks in terms of systems of late lexical insertion, thematic roles are essentially determined by functional elements, such as voice or v, possibly with different "flavours", fixing the argumental properties of their immediate dependents: Ramchand 2008, Harley 2010, Marantz 2012 and references quoted there). As for scope-discourse properties, things are less straightforward and different approaches have been considered. The approach adopted here is the criterial view (Rizzi 1991/2000, 1997), which addresses the problem in a structural way analogous to the assignment of thematic roles: the left periphery is populated by a system of functional heads dedicated to the expression of scope-discourse properties: Q, Top, Foc, etc. So, the sentences in (1) actually have representations like the following:

(2) a. Which book Q should you read < which book $>$ ?

b. This book TOP you should read $<$ this book $>$ tomorrow

c. THIS BOOK FOC you should read $<$ this book> (, not that one) 
Such heads have the syntactic role of triggering movement of a phrase bearing the relevant criterial feature to their Spec position; and the interface function of triggering the application of interpretive routines at the interfaces with sound and meaning. They determine the interpretation of the derived structures in terms of the interpretive articulations of operator-scope domain, topic-comment, focuspresupposition, respectively; and, at the interface with sound systems, they trigger the application of rules for the assignment of the appropriate intonational contours (Bocci 2012).

This conception is sometimes said to "syntacticize" scope-discourse semantics, in the sense that it expresses interpretively relevant configurations (topiccomment, etc.) in a uniform syntactic format Specifier-head-complement, thus adopting fully transparent interface representations. Syntactic representations are organized for the expression of such properties, with criterial heads giving simple instructions to the interpretive systems ("interpret my specifier as the topic and my complement as the related comment", "interpret my specifier as (contrastive) focus and my complement as presupposition", etc.), thus considerably simplifying the interpretive computation at the interfaces.

This structural view of the expression of scope-discourse semantics is immediately supported by the existence of languages in which the criterial heads are overtly expressed, with overt Q, Top, Foc markers, and also special complementizers for relatives, for exclamatives, for comparatives, and other kinds of $\mathrm{A}^{\prime}$ constructions:

(3)

$\begin{array}{llll}\text { a. Ik weet niet [wie of } & \text { (Dutch varieties, Haeg } \\ \text { 'I know } & \text { not who Q } & \\ \text { [ Jan } & \text { gezien heeft ]] } & \\ \text { Jan } & \text { seen has' } & \\ \text { b. Un sè } & \text { [do [ dan } & \text { (Gungbe, Aboh 2004) } \\ \text { 'I heard that snake } & \\ \text { lo yà [ Kofi hu ì ]]] } & \\ \text { the TOP Kof killed it' } & \\ \text { c. Un sè } & \text { [do [ dan } & \text { (Gungbe, Aboh 2004) } \\ \text { 'I heard that snake } & \\ \text { lo wè [ Kofi hu } & \\ \text { the FOC Kofi killed' } & \end{array}$

Under the uniformity guidelines that guide modern comparative syntax, the natural initial assumption, to be abandoned only on the basis of clear disconfirming evidence, is that all languages use a similar system of syntactic markers, except that such markers may be overt or not; this is a spell-out parameter, a familiar 
and widely attested kind of low level parametrisation. As usual, a strong uniformity assumption is the natural starting point in the comparative work, in fact the only starting point which really makes comparative syntax a feasible enterprise; and, as usual, as analysis proceeds, the initial assumption will have to be weakened under the pressure of empirical evidence, various kinds of non trivial parametrisations will have to be integrated, etc. We will come back to some cases below. In the case of left peripheral structures, much work of the last decade has confirmed the view that a strong uniform core, expressed by the criterial system, can be fully maintained across languages: see, e.g., Rizzi (1997, 2000, 2004a-b), Belletti, (2004a-b, 2009), Poletto (2000), Laenzlinger (2002), Cinque (2002), Benincà and Munaro (2008) on Romance, and Grewendorf (2002), Haegeman (2012) on Germanic; and then, Roberts (2004) on Celtic, Krapova \& Cinque (2004) on Slavic, Puskas (2000) on Finno-Ugric, Shlonsky (1998) on Semitic, Frascarelli and Puglielli (2010) on Cushitic, Aboh (2004), Biloa (2012), Bassong (2012), Torrence (2012) on African languages, Durrleman (2008) on Creole, Jayaseelan (2008) on Dravidian, Tsai (2007), Paul (2005), Endo (2008), Saito (2010) on East Asian, Pearce (1999) on Austronesian, Speas \& Tenny (2003) on American Indian, in addition to much work in Romance and Germanic dialectology (e.g. Cruschina 2012), and on Classical languages and diachrony (Salvi 2005, Danckaert 2012, Benincà 2006, Franco 2010), etc. See Cinque \& Rizzi 2010, Shlonsky 2010 for general overviews.

\section{Alternatives: "pragmaticize” an impoverished syntax?}

In the criterial conception, Top, Foc, Q markers, etc. are functional heads which populate the left periphery of the clause, much as the IP space is populated by auxiliaries and particles expressing modality, tense, mood, aspect, voice, etc.. Such heads guide computations in syntax and interpretation. Moreover, the criterial heads can co-occur, sometimes in fixed orders, giving rise to complex maps of the left periphery ${ }^{1}$. Consider for instance the following map incorporating several

\footnotetext{
1 The reference to unqualified topic positions should be refined if a more detailed typology of topic positions and their interpretive properties is taken into account: Benincà \& Poletto 2004, Frascarelli \& Hinterhoelzl 2007, Bianchi \& Frascarelli 2010). Similar refinements are needed for the landing site of wh-movement. E.g., Munaro and Pollock (2005), Poletto and Pollock (2004), Obenauer and Poletto (2000) have shown that different kinds of wh-operators target different positions in the left periphery, a result very much in line with the spirit of cartographic studies. I will not address these important refinements here. But see also the remarks and references on the special position of why in many languages in section 5 .
} 
left peripheral elements in Italian, with specialized positions for topics, foci, highlighted adverbials sandwiched in between the two delimiting heads of Force and Finiteness:

(4) Credo $\left[_{\text {ForceP }}\right.$ che $\left[_{\text {TopP }}\right.$ a Gianni Top $\left[_{\text {FocP }}\right.$ IL MIO LIBRO Foc $\left[_{\text {ModP }}\right.$ domani Mod [IP Piero gli dovrebbe dare]]]]]

'I believe that to Gianni MY BOOK tomorrow Piero should give'

What alternative approaches should this view be compared to? As usual, it is instructive, at least as a starting point, to compare alternatives that polarize the options, in order to optimally clarify the conceptual debate.

A radical alternative could be to go the opposite way, and "pragmaticize" an impoverished syntax. Consider, for instance, a system of functional heads assuming just C and I, as in the mid-1980's, a system adopted, with the addition of $\mathrm{v}$ and the relabeling of I as $\mathrm{T}$ by much minimalist syntax, sometimes with the explicit proviso that this may be seen as an abbreviation for a richer representational system (e.g., in Chomsky 2000, fn. 31). But let's now take the C I V (or C T v V) system at face value. How could basic properties of left-peripheral syntax be expressed through such an impoverished system of functional heads? Clearly, topics, foci and preposed adverbs can occur between the complementizer that and the subject, so the system should make room for such elements. A traditional option is to assume that multiple adjunction is possible. So, we could have representations like

(5) Credo $\left[_{\mathrm{CP}}\right.$ che $\left[_{\mathrm{IP}}\right.$ a Gianni $\left[_{\mathrm{IP}}\right.$ IL MIO LIBRO $\left[_{\mathrm{IP}}\right.$ domani $\left[_{\mathrm{IP}}\right.$ Piero gli dovrebbe dare]]]]]

Such a radically less informative syntax would have to shift much of the computational burden to the other side of the interface through rich interpretive mechanisms, capable of assigning different interpretations (topic, focus, etc.) to identical structures (the adjoined position), of expressing ordering constraints (topic higher than focus, as is the case in many languages), cooccurrence restrictions, and parametrisation (a single topic in some languages, a proliferation in other languages).

I would like to review here two extremely simple arguments in favor of the rich cartographic view:

1. Such overt markers as Top, Foc, Q, Rel, etc. in languages like those in (3) have a definite status and role in the cartographic system, while they are not naturally integrated into the impoverished syntax view;

2. Many languages offer straightforward evidence of $\mathrm{C}$ particles occurring in different positions, and sometimes co-occurring in fixed orders, properties which are inconsistent with a "single C" approach. 


\section{Could criterial heads be reanalyzed as DP internal particles?}

How could an "impoverished syntax" analysis treat overt focus, topic, Q markers, etc. in cases like (3)? The only viable option would seem to be to reanalyze them as DP-internal, i.e. case-like elements (or postpositions) attached to DP's, and expressing certain scope-discourse properties. The distributional properties of such elements could not be determined within the impoverished syntax, but would be checked post-syntactically, in the interpretive component.

While for some specific cases this may well be the correct analysis (Durrleman 2008), it does not hold in general, particularly not for the cases in (3).

There is straightforward evidence that such particles are confined to the left periphery. Gungbe does not allow for multiple wh-questions or bona fide in situ questions, but it does permit wh-in situ echo questions like (6b). In this case, the wh-phrase, while undoubtedly focal, cannot bear the focus marker. This would not be expected if wè was a DP-internal marker, while it follows from the view that wè is a DP-external left peripheral head, attracting wh-phrases and other focal elements:

(6) a. fíté wè é yì?

'Where Foc he went?'

b. é yì fíté (*wè)?

'he went where (foc)?'

Analogously, such particles as of in Dutch varieties typically occur adjacent to left-peripheral wh elements, but not on wh- in situ (as in (7)), and they are inconsistent with V-2, hence presumably compete with the moved verb (as in (8b)); these properties would not be expected if the particles were DP-internal (or postposition-like), whereas they follow from the hypothesis that they are independent heads in the left periphery ${ }^{2}$ :

$\begin{array}{lllllllll}\text { (7) Ik vraag } & \text { me } & \text { af } & \text { [ wie of } & \text { wat } & \left({ }^{\star} \text { of }\right) & \text { gezegd } & \text { heeft }] \\ \text { 'I ask } & \text { myself } & \text { off } & \text { who of } & \text { what } & \left({ }^{\star} \text { of }\right) & \text { said } & \text { has' }\end{array}$

2 Thanks are due to Enoch Aboh and Liliane Haegeman for providing and discussing the data of Gungbe and of the Dutch varieties analyzed in this section. 
(8) a. Ik weet niet [ wie of [Jan__ gezien heeft]]

'I know not who of Jan seen has'

b. Wie ( ${ }^{\star}$ of $)$ heeft Jan ___ gezien?

'Who has Jan seen?'

\section{Different C-elements occupying distinct positions}

One initial motivation for cartographic representations was that different elements traditionally analyzed as complementizers clearly occupy distinct positions. For instance, che and its infinitival counterpart di in Italian (Rizzi 1997, based on Kayne 1983, Rizzi 1982):

(9) a. Ho deciso che parlerò a Gianni domani

'I decided that I would speak to Gianni tomorrow'

b. Ho deciso di parlare a Gianni domani

'I decided di to speak to Gianni tomorrow'

Now, a topicalized element (in the Clitic Left Dislocation, or ClLD, construction) naturally occurs after che (in fact it can only occur after che in more restrictive varieties like mine), while it can only occur before $d i$ :

(10) Ho deciso che, a Gianni, gli parlerò domani

'I decided that, to Gianni, I will speak tomorrow'

(11) a. Ho deciso, a Gianni, di parlargli domani

'I decided, to Gianni, di to speak tomorrow'

b. *I deciso di, a Gianni, parlargli domani

'I decided di, to Gianni, to speak tomorrow'

Consider now the complementizer marking yes/no embedded questions, se (if). It can be both preceded and followed by a topic (and also surrounded by topics in the same sentence):

(12) a. Non so, a Gianni, se gli potremo parlare

'I don't know, to Gianni, if we could speak to him'

b. Non so se, a Gianni, gli potremo parlare

'I don't know if, to Gianni, we could speak'

c. Non so, a Gianni, se, il tuo libro, glielo potremo dare

'I don't know, to Gianni, if, your book, we could give' 
So we have the following orderings:
a. Che Top $\ldots$
b. ... Top se Top ...
c. ... $\quad \ldots$ Top di

An adjunction-based theory can hardly express such constraints: how could the lexical choice of $\mathrm{C}$ determine if adjunction must take place to $\mathrm{CP}$, or to IP, or to both? On the contrary the ordering constraints of topics and $\mathrm{C}$ particles come out naturally from an articulated view of the $\mathrm{C}$-space, with che and di delimiting the space possibly occupied by topics (and other left-peripheral material), and se occurring in the middle, thus permitting both lower and higher topics:

(14) ...che ... (Top) ... se ... (Top) ... di ...

Here, ordering constraints can be stated by using independently needed mechanisms (head-complement selection, in some cases a primitive and parametrizable property, in other cases a property amenable to further principled explanation), and we do not have to enrich the theory of adjunction to make the adjunction sites contingent on the lexical properties of the complementizer (actually, we don't need to assume a theory of adjunction at all, as in Kayne 1994, the relevant configurations reducing to specifiers, heads and complements). In the analysis proposed in Rizzi (1997) the two delimiting particles che and di are denominated Force and Fin(iteness), respectively: Force connects to the illocutionary Force, or to the clause-typing properties (Cheng 1997, Zanuttini \& Portner 2003), which a higher selector must be sensitive to: declarative, question, exclamative, etc.. Fin expresses the finite or non-finite character of the adjacent clause. The space delimited by Force and Fin is populated by intermediate heads, such as Top, and also heads hosting particular operators. Se is analyzed as an Int(errogative) head, hosting the yes/no question operator and a small number of base-generated whelements such as perché ('why', Rizzi 2001 and the refined approach in Shlonsky and Soare 2011). At first sight it may seem surprising that Int is in a position distinct from (and lower than) Force; but Int should not be confused with the marker of interrogative Force, which plausibly appears in the highest position of the Csystem (Force): rather, it is a position hosting a certain kind of operator (yes/no, reason), which is connected to, but distinct from, the Force position. That interrogative Force and the position hosting interrogative operators must be distinguished is straightforwardly shown by the fact that ordinary wh-elements, in Romance and in many other languages, appear to target the Foc position, lower than Int and (a fortiori) than Force. We thus arrive at a partial map such as 
(15) Force... Int ... Fin

With the possibility of connecting these heads via a Search (Agree-like: Chomsky 2000) relation, ensuring featural consistency: for instance, Int must be related to a Force node specified as "interrogative", which will in turn be accessible to a higher selector, requiring an indirect question. E.g., in (12a) we will have

non so [ Force ${ }_{\text {+interrogative }}\left[\right.$ a Gianni Top $\left[\operatorname{Int}_{\text {se }}[\ldots \ldots\right.$

\section{Cooccurrence of C-elements}

It should be observed here that the inference from (13) to (14) depends on transitivity assumptions (if A is higher than B and B is higher than C, then A is higher than C) whose legitimacy has been called into question (van Craenenbroeck 2006, 2009). We will come back to this point. Be it as it may, the hypothesis of a complex C-system consisting of distinct heads is straightforwardly corroborated by cases in which distinct particles co-occur in the same structure. For instance, Roberts (2004) observes that in Welsh the sequence of topics, foci, etc. is sandwiched in between the two particles mai and $a$, which in his analysis delimit the complementizer system:

$\begin{array}{lllllll}\text { Dywedais } & \text { i } & \text { [mai 'r dynion fel arfer a } & \\ \text { 'Said } & \text { I } & \text { C } & \text { the men as usual } & \text { C } & \text { (Welsh: Roberts 2004) } \\ \text { [werthith } & \text { y } & \text { ci ] ] } & & & & \\ \text { will-sell the } & \text { dog' }\end{array}$

Under (15), this case is naturally analyzable as a language simultaneously lexicalizing the two delimiting particles Force and Fin. A case of simultaneous lexicalization of Force and Int is provided by the following Spanish construction:

(18) Me preguntaron que si tus amigos ya te visitaron en Granada 'They asked me that if your friends had already visited you in Granada’ Plann (1982), Suñer (1994)

The sequence que si cannot be treated as reanalyzed as a single unit because other elements (a topic, a preposed adverb) can interpolate between the two, as in $(19 a-b)$; (19c-d) illustrate the same construction with a wh-question introduced 
by que followed by an interpolated topic (I am indebted to M. Lluïsa Hernanz for data and useful discussion of this construction):

(19) a. María me dijo que el salmón si lo quería a la plancha o hervido 'Maria told me that the salmon if (I) wanted it roasted or boiled'

b. María preguntó que el lunes si había periódicos 'Maria asked that the Monday if there were newspapers'

c. María dijo que a Juan cuándo lo operaban 'María said that Juan when (they) operated him'

d. Le pregunté que Juan cómo cocinaba 'I asked him/her that Juan how cooked'

According to Plann's (1982) analysis, such embedded questions introduced by the complex form que si (or que wh) are interpreted as "reported question": María asked me the question "Do you want the salmon roasted or boiled?", and I report this speech event as in (19a). Si marks the status of the clause as a yes/no question, and que marks the reported character of it. Coherently with this interpretation, verbs taking indirect questions which are not also verbs of saying (forget, remember, etc.) do not enter into this construction.

Saito (2011) analyzes the Japanese equivalent of (18)-(19) as involving a higher head marking the "reported" character of the embedded clause (to), and a lower head marking its interrogative character $(k a)$, the mirror image of the order illustrated by que si, as a consequence of the headedness properties of the two languages:

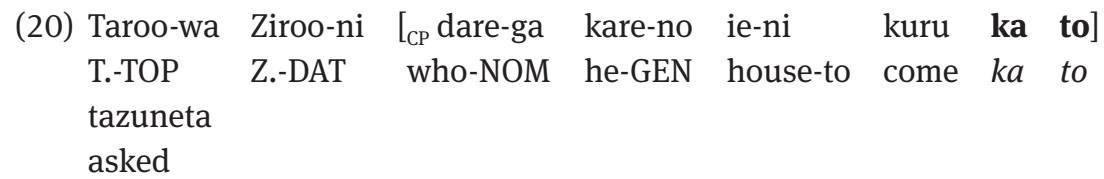

'Taroo asked Ziroo that who is coming to his house'

In cases like (18)-(20) the lower interrogative specification is presumably transferred to the higher head through the mechanism discussed in connection with (16), which thus characterizes the structure as a reported question, a complex specification which can be selected by a higher verb like ask, but not by believe (which doesn't take a question), nor by forget (which does not involve a speech act)

If some languages instantiate the ordering that if, the opposite order if that is also found cross-linguistically, e.g. in Dutch varieties in which the sequence wie of dat (who if that) alternates with wie of in cases like (4a), and also with wie dat, a familiar case of "multiply filled Comp", in traditional terminology: 
(21) Ik weet niet [wie of dat

'I know not who Q that (Dutch varieties, Haegeman 1994)

[ Jan___ gezien heeft]]

Jan seen has'

If (18)-(20) can be seen as a lexicalisation of Force and Int, (21) presumably lexicalizes Int (or Foc, or whatever head hosts the wh-element in its Spec in Dutch) and Fin.

How can what looks like "the same element" occur in distinct positions, before and after if in different languages? Clearly, (the equivalent of) that is an unmarked, versatile complementizer form, capable of occurring in the highest $\mathrm{C}$ position, and also, in cross-linguistically variable manners, in lower positions, as in (21), or with wh-exclamatives in Italian, as in (22) (the only case of legitimate “doubly filled Comp” in Standard Italian):

(22) Che bel libro che ho letto!

'What a nice book that I have read!'

Distinct occurrences of that can in fact also co-occur in a higher and a lower position, as with preposed adverbial clause in English varieties admitting (23a) (McCloskey 1992, Rizzi 2010, Radford 2011), with certain topics in the old southern Italian dialects discussed by Ledgeway (2003), or in the northern dialects in Paoli (2003), as in (23b-c); with embedded focus in Brazilian Portuguese (Mioto 1999), as in (23d),

(23) a. I thank that, if they arrive on time, that they will be greeted (McCloskey 1992, Radford 2011)

b. Le mandò a dire che tutte quille dinare che le voleva dare re de Franza per l'armata

'He sent (someone) to tell him that all this money that the king of France wanted to give him for the army’ (Old Southern Italian varieties, Ledgeway 2003, 131)

c. A chërdo che, col liber, ch' a l' abia già lesulo

'They believe that s/he has already read that book' (Turinese, Paoli 2003, cit. in van Craenenbroeck 2006)

d. A Joana acha que A MARIA (que) o João encontrou no cinema 'Joana thinks that MARIA João met in the cinema' (Brazilian Portuguese, Mioto 1999) 
So, that-like elements are able to lexicalize distinct positions in the C-space. Once this is recognized, potential "transitivity paradoxes" (van Craenenbroeck 2006) disappear.

Radford (op. cit.) discusses the possibility that that-like elements may lexicalize just Force or Fin (or both). This would be consistent with the fact that che is not necessarily adjacent to the exclamative phrase in Italian (Benincà 2001):

(24) Che bel biglietto, ieri, che ho trovato sul tavolo!

'What a nice note, yesterday, that I found on the table!'

with the preposed adverbial ieri attracted to a Mod head in the low left periphery of the clause, and che presumably lexicalizing Fin in this case.

In conclusion, the simultaneous lexicalization of more than one $\mathrm{C}$ particle, a common phenomenon across languages, raises an obvious problem for an "impoverished syntax" approach assuming a single C head, while it is expected under a richer cartography of the $\mathrm{C}$ system. One traditional analysis of cases with multiple C-particles would be to assume that "CP recursion" is involved in such cases. But the $\mathrm{CP}$ recursion idea, as such, is not specific enough to capture the different properties of the higher and the lower C-particles, e.g., in (19), (21), (23), etc.. As soon as distinct C-particles are assumed, with distinct properties and capable of selecting other C particles, a "CP recursion" approach would become indistinguishable from the cartographic analysis (calling "CP recursion" the complex cases we have seen would be analogous to calling "IP recursion" the cases of structures involving distinct inflectional heads in a fixed order, say with T, M, Asp markers, a conceivable but not particularly revealing terminological choice). In fact, the $\mathrm{CP}$ recursion idea can be seen as the first step toward a full-fledged cartographic analysis of the complementizer zone (e.g., as in Rizzi \& Roberts 1989, Nakajima 1992, Browning 1996).

\section{Types of "further explanation" of the functional sequence: the role of interface and locality principles}

Why is it that we typically find certain orders and cooccurrence restrictions in the functional sequences, rather than others? It is unlikely that the functional hierarchy may be an absolute syntactic primitive, unrelated to other requirements or constraints: why should natural language syntax have evolved to express such a complex and apparently unmotivated primitive? It is more plausible that the 
functional hierarchy (to the extent to which it is universal), and its ordering and cooccurrence restrictions may be rooted elsewhere (Cinque \& Rizzi 2010). So, it is natural and desirable to seek "further explanations" going beyond the mere observation of the properties of the functional sequences.

External factors such as interpretive requirements operating at the interface may be relevant in some cases. An early attempt to find a "further explanation" of the uniqueness of the left-peripheral focus position was sketched out in Rizzi (1997). In Italian, the left peripheral contrastive focus position is unique, as shown in (25), in sharp contrast with the possible proliferation of topic positions (see (26)):

(25) a. A MARIA devi dare il tuo libro (, non a Giulia) 'TO MARIA you should give tour book, non to Giulia'

b. IL TUO LIBRO devi dare a Maria (non il disco) 'YOUR BOOK you should give to Maria, not the record'

c. *A MARIA (,) IL TUO LIBRO devi dare (non a Giulia, il disco) 'To Maria your book you should give, not to Giulia the record'

(26) A Maria, il tuo libro, glielo darò domani

'To Maria, your book, I will give tomorrow'

Uniqueness of focus seems to hold for left-peripheral focus also in historically distant languages (e.g., Romance, Finno-Ugric, Puskas 2000, Kwa, Aboh 2004, Creole, Durrleman 2008, etc.). Of particular interest is the comparison with Abidji (Hager 2013). This language, like Gungbe, has overt topic (ćḱ) and focus (bé) markers. Like Italian, it permits a proliferation of topics, each followed by its topic marker, as in (27); but (overtly marked) focus must be unique, as in (28): ${ }^{3}$
a. kòfí è pìpjé òkókò $\dot{\varepsilon}$
Kofi MA peel.RES banana Def. « Kofi peeled the banana.»

b. òkókò $\dot{\varepsilon}_{\mathrm{i}} \quad$ ćké kòfí è pìpjé nì banana Def. Top Kofi MA peel.RES pron. $_{{ }_{\mathrm{i}}}$ «The banana, Kofi peeled it. »

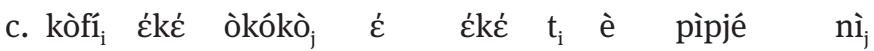
Koff $_{\mathrm{i}}$ Top banana ${ }_{\mathrm{j}}$ Def. Top $\mathrm{t}_{\mathrm{i}}$ MA peel.RES pron «Kofi, the banana, he peeled it.»

3 Incidentally, the multiple occurrence of the topic particle in cases like (27c) argues for the view that multiple topics arise through a possible recursion of TopP (as in Rizzi 1997), rather than through a mechanism permitting a simple Top head with multiple specifiers. 
(28) a. kòfí è pìpjé òkókò ह́

Kofi MA peel.RES banana Def.

« Kofi peeled the banana. »

b. òkókò $\dot{\varepsilon}_{\mathrm{i}}$ bé kòfí pìpjé

banana Def. Foc Kofi peel.RES

«THE BANANA, Kofi peeled

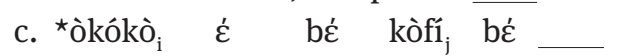

banana $_{\mathrm{i}}$ Def. Foc Kofi $\mathrm{j}_{\mathrm{j}}$ Foc

pìpjé

«THE BANANA, KOFI peeled

peel.RES "

In Rizzi (1997), the hypothesis was put forth that uniqueness of focus could follow from the interpretive properties of the structure, as stated in a rudimentary form in the interpretive instruction in (29): if a FocP was recursively embedded as the complement of a higher Foc, we would have that the complement of a higher Foc head (underscored in (30)), a presupposed part according to (29), contains a focus position, an inconsistent interpretive property.

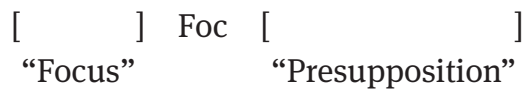

(30) *[A MARIA] Foc1

'TO MARIA

$\frac{[\text { [ IL TUO LIBRO ] Foc2 [ devi dare ] ] ] }}{\text { your book }}$

As an element cannot be simultaneously focused and a component of the presupposed part, Focus recursion, which would inevitably yield this clash, is excluded in principle. No comparable requirement would affect Topic recursion. The interpretive instruction in this case is (31):

$$
\left[\begin{array}{l}
{[} \\
\text { "Topic" Top [ }
\end{array}\right.
$$

Now, the notion "comment" puts very few restrictions on content and informational structure: about anything can be a comment, provided that an "aboutness" relation to the topic can be established. In particular, nothing precludes a comment to be internally articulated as a topic - comment structure. So, no interpretive requirement seems to preclude a Top recursion structure:

(32) [A Maria] Top1 [ [il tuo libro] Top2 [glielo devi dare immediatamente ]]] 'To Maria your book you should give immediately' 
In addition to principles operating at the interfaces, other kinds of principles are plausibly relevant for providing "further explanations" of aspects of the sequence. Abels (2012) claims that (almost) all the ordering effects observed in the Italian left periphery follow from the theory of locality (based on a version of featural Relativized Minimality (RM) inspired by Starke 2001, Rizzi 2004, building on Rizzi 1990). Consider for instance the fact that Int, realized as se, can precede a contrastive focus (Int-Foc), but the opposite ordering is impossible ( ${ }^{\star}$ Foc-Int):

(33) a. Non so se proprio QUESTO volessero dire (e non qualcos'altro) 'I don't know if exactly THIS they wanted to say (and not something else)'

b. ^Non so proprio QUESTO se volessero dire (e non qualcos’altro)

'I don't know exactly THIS if they wanted to say (and not something else)'

This ordering constraint can naturally follow from RM, as the question operator expressed in Int would induce a minimality effect on focus, also an operator construction, thus ruling out (33b). Locality thus provides a plausible "further explanation" for a property of the left-peripheral sequence, an important and welcome result. ${ }^{4}$

Along similar lines, Haegeman (2012) accounts for the inapplicability of topicalization in various kinds of embedded domains in English as a consequence of locality, expressed as featural RM. This kind of locality-based explanation is fully consistent with detailed cartographic representations, in fact it presupposes them.

The possibility of a "further explanation" of the sequence is sometimes seen as an anti-cartographic result, but it is not. If the relative ordering of the elements can be derived from a natural theory of locality or from interface considerations (an option to be carefully explored, and hopefully correct), this does not make the functional sequence an artifact: the sequence is an "object of the world" and an accurate map of the sequence is the essential point of departure for further study, including the search for further explanation. Consider an analogy with the sequence of DNA: once we have a map of the sequence, particular subsequences may be amenable to "further explanations" in terms of fundamental physical/ chemical laws, or evolutionary theory: but the ordering is a real, substantive

4 Abels (op. cit.) compares a locality based approach with what he calls a "templatic" approach, stipulating the hierarchical order as a primitive. In fact, as far as I can tell, no one ever proposed a "templatic" approach in this sense. All cartographic discoveries on the left-peripheral hierarchy explicitly or implicitly assumed the possibility of further explanations for the observed hierarchy, stemming either from interface considerations or independent grammatical principles. 
component of organisms, not an ephemeral artifact. So there is no inconsistency between the endeavor of drawing precise cartographic maps and the attempt to pursue "further explanations" of cartographic properties: in fact the two research aims presuppose and complement each other.

\section{On the possible relevance of locality: constraints on the English left periphery}

Italian freely allows multiple topics of different kinds, including DP topics in any order:

(34) a. Gianni, la tua macchina, lo ho convinto a comprarla 'Gianni, your car, I convinced to buy'

b. La tua macchina, Gianni, lo ho convinto a comprarla 'Your car, Gianni, I convinced to buy'

In English, while more than one element can be fronted in certain cases (see below), structures with multiple topical DP's are deviant (Rachel Nye and Ian Roberts, p.c.):

(35) a. John, I convinced to buy your car

b. Your car, I convinced John to buy

c. ^John, your car, I convinced to buy

d. *Your car, John, I convinced to buy

This difference could be a case of primitive parametric choice (Top recursive or not), but the possibility of a "further explanation" of this contrast between English and Italian is worth exploring. There is a major independent difference between the topicalization constructions in the two languages which we may appeal to. In Italian, a topicalized direct object is obligatorily resumed by a clitic, while no resumption is required in English:

(36) a. *Il tuo libro, ho comprato ieri 'Your book, I bought ___ yesterday'

b. Your book, I bought ___ yesterday

Cinque (1990) explained the obligatoriness of clitic resumption in Italian through the following theoretical ingredients: 
(37)
a. Variable $=\left[_{D P}\right.$ ] locally A'-bound
b. A variable must be bound by an operator.

If $\mathrm{A}^{\prime}$-bound gaps are syntactic variables (as per definition (37a)), the impossibility of (36a) may be linked to the fact that Topics are not operators inherently: they are just referential DP's. Therefore, (36a) is excluded because it contains a variable which is not operator-bound, as (37b) would require: natural languages don't permit free (unbound) syntactic variables, possibly a consequence of Full Interpretation (Chomsky 1986; consider also Koopman \& Sportiche’s 1983 Bijection Principle).

If a clitic is present, as in (38), the gap is not locally $\mathrm{A}^{\prime}$-bound because its local binder is the clitic, hence the gap does not qualify as a syntactic variable under (37a), and we only have a legitimate chain of local referential dependencies connecting the topic, the clitic and the gap: ${ }^{5,6}$

$$
\begin{aligned}
& \text { Il tuo libro, lo leggerò ___ domani } \\
& \text { 'Your book, I will read it tomorrow' }
\end{aligned}
$$

Notice that, much as in Italian, a resumptive pronoun is obligatory in Gungbe object topicalization (while a gap is fine in focalization: Aboh 2004). The same account extends to this case.

What about English? Cinque (1990) builds on Chomsky (1977) assuming that Topicalization constructions in English use a null operator NO (possibly akin or

5 The Romance Clitic Left Dislocation construction is glossed with a pronoun in object position in English, but the gloss may be misleading: English has an independent construction, called Left Dislocation by Ross (1967), involving a topic resumed by a pronoun in argument position, which has quite different properties from Romance CILD (e.g., lack of connectivity effects), and is more similar to the construction referred to as Hanging Topic in Cinque (1990). The closest functional equivalent of Romance CILD is Ross's (1967) Topicalization illustrated by (36b).

6 If we assume the copy theory of traces, with a variable defined as a locally A'-bound occurrence, the same conclusion holds if the clitic and the topic are externally merged as a "big DP" [lo [il tuo libro]] (Belletti 2009, chap. 8), from which the two elements reach their final destination (respectively, the Top position and the clitic position), with local referential dependencies connecting the topic, the clitic, the clitic trace, the topic trace. Again, as the topic trace is not locally $\mathrm{A}^{\prime}$-bound, it does not qualify as a variable:

(i) [Il tuo libro $]_{\mathrm{i}}$, lo $\mathrm{o}_{\mathrm{i}}$ leggerò $\left[<\mathrm{lo}_{\mathrm{i}}>\left[<\mathrm{il}\right.\right.$ tuo libro $\left.\left._{\mathrm{i}}>\right]\right]$ domani

For the sake of clarity I use indices in the preceding representation, but the crucial point is the existence of a necessary referential dependency between the clitic and the DP (and the fact that the whole chain is the unique recipient of the patient theta role). The choice of a particular formal device to express this obligatory dependency is not crucial. 
identical to the one found in appositive relatives, easy to please constructions, parasitic gaps, etc.), here playing the role of the functional equivalent of the clitic to establish a successful syntactic connection between the topic and the object gap:

(39) Your book NO I bought yesterday

The null operator rescues the structure from a violation of (36b), as the variable is now bound by an entity formally characterized as an operator, much as in an appositive relatives in languages which use a null operator in this construction (i.e., Italian: Gianni, NO che ho appena conosciuto ... 'Gianni, NO that I have just met ...').

It can be noted here that some languages validate this analysis by having an overt variant of the NO in topicalization, e.g., Dutch (Koster 1978), with the optional occurrence of the relative pronoun:

(40) Die man (die) ken ik

'That man, I know'

Under this analysis of English topicalization, a representation with a double topic would look like the following:

(41) *John NO, your book NO, I convinced to buy

This representation triggers a Relativized Minimality effect, with the higher NO crossing over the lower one. Hence double DP topics in English are excluded by the theory of locality. No such problem arises in the Romance languages, which do not use null operators in this construction. ${ }^{7}$

7 Richard Kayne (p.c.) informs me that he finds an improvement with multiple topics with shape "that kind of X": ?That kind of book, that kind of student, you'll never be able to convince to buy. Perhaps this construction marginally permits a kind of topic absorption, akin to the wh-absorption discussed by Higginbotham and May (1981) in the context of multiple whmovement constructions, permitting a single NO to be involved here. I will leave the question open. 


\section{Featural relativized minimality and topic-focus interactions}

Going back to Italian topicalization, the possibility of multiple DP topics in (34) can now be linked to the fact that the Italian construction does not involve a NO potentially triggering minimality violations. Still, the question arises, if the topic is moved to the left periphery, of why topic movement itself, taking place across another topic, does not trigger a minimality violation.

One radical possibility would be to assume that the topic is directly basegenerated (externally merged) in the left periphery (as in , e.g., Frascarelli 2000). Some considerations, though, make it more plausible that topics are moved to the LP also in ClLD: on the one hand, the construction is sensitive to strong islands (as originally observed by Cinque 1977):

(42) a. *?A Gianni, tutti ridevano mentre gli parlavo

'To Gianni, everybody laughed while I was talking'

b. *?A Gianni, vorrei contattare la ragazza che gli ha parlato

'To Gianni, I would like to contact the girl who spoke recently' da poco

Moreover, it shows reconstruction effects for anaphor binding (see Cecchetto 2000):

(43) a. Le proprie ${ }_{i}$ idee, $_{\text {Gianni }}$ le ha sempre difese con passione 'His own ideas, Gianni always difends passionately'

b. Certe voci su di sé ${ }_{i}$, Gianni $_{i}$ le ha sempre respinte con sdegno 'Certain rumors about himself, Gianni always denied with rage'

c. Fiero di sé, Gianni ${ }_{i}$ lo è sempre stato 'Proud of himself, Gianni has always been'

As sensitivity to strong islands and reconstruction are hallmarks of movement, it appears that the construction does involve movement. We are thus led to the conclusion that intervention locality is not operative on "pure" Top movement (while NO movement, much as other kinds of operator movement is sensitive to it). In Rizzi (2004) two options are explored to capture this lack of sensitivity: either an “equidistance" kind of mechanism (Chomsky 1995) allows one topic to escape from the domain of another topic, or featural Relativized Minimality is stated in such a way as to exempt the Top feature from the effect.

Whether one or the other device (or some other option) turns out to be correct for "pure" Top movement (see also the discussion of the issue in Endo 2007), the 
fact remains that the Italian construction differs from English Topicalization in not involving a NO, and this suffices to capture the observed contrast between the two languages in (not) permitting multiple topics.

Notice that in English a topicalized and a focalized DP cannot naturally cooccur in the left periphery:

(44) a. ??John NO, YOUR CAR I convinced to buy (not Bill's car)

b. ??Your car NO, JOHN I convinced to buy (not Peter)

Under our assumptions, the Topic DP needs a null operator; the focused DP may also use a null operator, or perhaps the +Foc feature suffices to turn any DP into an operator, which would make the NO mediation unnecessary.

If the latter conclusion is correct, why would two distinct attracting features, +Foc and whatever features characterize NO's, interact to give rise to minimality effects?

In the system of Rizzi (2004), RM is revised in terms of a system of superfeatures defining natural classes of morphosyntactic features as follows (in the reference quoted, the second feature class is called "quantificational", but I now use the term "operator" to include the NO in it, as seems natural):

(45) In ... X ... Z .. Y . . , a local relation between $X$ and $Y$ is blocked when

a. $Z$ intervenes between $X$ and $Y$, and

b. Z fully matches the specification of $X$ in terms of the superfeatures of (46).

(46) A classification of morphosyntactic features:

Argumental: Case, person, number, gender, ...

Operator: Q, Neg, Quant, Foc, NO,...

Modifier: Modality, Tense, Mood, Aspect, Voice, ...

Topic.

The definition of RM in terms of superfeatures, rather than directly in terms of the attracting feature (as in Chomsky 1995) is motivated there, among other reasons, in order to capture cases in which the intervener does not share the same exact feature as the moved element, and still an intervention effect is triggered, as in negative islands (47b) or movement from the domain of quantificational adverbials (47c): here the interveners clearly are not marked Q (or Wh), and still the case patterns with extraction from an indirect question (47d)) (the relevant French construction is discussed at length in Obenauer 1983 and reanalyzed in terms of RM in Rizzi 1990): 
(47) a. Combien ${ }_{\mathrm{Q}}$ a-t-il consulté [___ de livres]?

'How many did he consult of books ?'

b. * ${ }^{\star}{ }$ mbien $_{\mathrm{Q}}$ n'a-t-il pas $\mathrm{Neg}_{\mathrm{Neg}}$ consulté [ de livres] ?

'How many did he not consult of books ?'

c. ${ }^{\star}$ Combien $_{Q}$ a-t-il beaucoup ${ }_{\text {Quant }}$ consulté [ de livres] ?

'How many did he a lot consul of books ?'

d. ${ }^{\star}$ Combien $_{\mathrm{Q}}$ se demande-t-il [ comment ${ }_{\mathrm{Q}}$ consulter [ __ de livres] ?

'How many does he wonder how to consult of books?'

We can now use this system to account for the degraded status of (44): NO and Foc belong to the operator class, hence a minimality effect is produced when one crosses over the other.

So, the order Top-Foc, very frequently attested across languages, is degraded in English. ${ }^{8}$ In fact, we expect it to be generally unavailable, or degraded, in languages using NO for topicalization.

On the contrary, the cooccurrence Top-Foc is possible in the Italian left periphery:

(48) a. Gianni, LA TUA MACCHINA lo ho convinto a comprare , non quella di Franco

'Gianni, YOUR CAR I convinced to buy, not Franco's'

b. La tua macchina, GIANNI ho convinto 'Your car, GIANNI I convinced to buy, not Piero' a comprarla, non Piero

This is expected because in this type of language Top does not involve a NO (as independently shown by the obligatory presence of the resumptive clitic), hence no minimality effect is triggered by an intervening element belonging to the operator class like Foc.

8 The degradation of Top Foc in (44) is typically judged less severe than the degradation of Top Top in $(35 \mathrm{c}-\mathrm{d})$. If this gradation is reliable and representative, the system of featural RM may provide a natural way to capture it, as (35) involves an intervener and a target defined by the same morphosyntactic feature (whatever the exact characterization of NO may be), while (44) involves two elements defined by distinct features belonging to the same feature class. Much recent work on language acquisition based on Friedmann, Belletti \& Rizzi 2009, Belletti, Friedmann, Brunato, Rizzi 2012 in fact exploits the capacity of featural RM to make fine-grained distinctions on a scale from fully well-formed to completely excluded. 


\section{Topics and PP preposing}

The incompatibility of two topics basically holds of two (or more) DP's: a DP can co-occur with a PP with topic-like interpretation in a fixed order:

(49) Words like that, in front of my mother, I would never say

Presumably, the PP does not need a NO because a null PP, contrary to a null DP, is not (automatically) classified as a syntactic variable. Consider also the fact that in Italian the clitic, obligatory with the DP, becomes optional with the PP:

(50) a. Di Gianni, (ne) parlerò domani

'Of Gianni, I will speak tomorrow'

b. A Gianni, (gli) parlerò domain

'To Gianni, I will speak tomorrow'

the PP presumably can target a Mod head in the low CP zone (typically used for highlighting an adverbial which is neither proper topic nor focus: Quickly, John left the room; but presumably preposed PP's can also target higher positions in the left periphery, possibly akin to Beninca' \& Poletto's (2004) Scene Setting position, perhaps characterized by a (differently flavored) Mod head). An element in Spec Mod is not an operator, according to the classification in (46), so movement of NO across it is possible:

(51) Words like that NO, in front of my mother Mod, I would never say

If PP's can be attracted to the Mod positions of highlighted adverbials in the left periphery, then they won't interfere with a NO chain in (51), under the formulation of RM in (45)-(46).

Independent evidence that preposed PP's can target a position distinct from the topic position is provided by anti-adjacency effects (Browning 1997, Rizzi 1997). An adverbial intervening between that and the subject position (in the Spec of a Mod head in the updated analysis of Rizzi 2010, building on Rizzi 2006, Rizzi \& Shlonsky 2007) alleviates a that-trace effect, as in (52b), while an intervening topic does not improve the acceptability of the sentence, as in (52c):

(52) a. *This is the man who I think that will sell his house next year

b. This is the man who I think that, next year, will sell his house

c. *This is the man who I think that, his house, will sell next year 
The adverbial facts can be reproduced when a PP like the one in (51) is preposed, again in contrast with the case of DP topicalization:

(53) a. *This is the man who I think that would never say words like that in front of my mother

b. This is a man who I think that, in front of my mother, would never say words like that

c. ${ }^{\star}$ This is the man who I think that, words like that, would never say in front of my mother

So, this provides additional evidence that the preposed PP does not target Top, but Mod, thus corroborating the analysis of the compatibility of the preposed PP with a topic DP in (51). ${ }^{9}$

\section{Conclusion}

The criterial approach to scope-discourse semantics, supported by the wellattested cases of overt realization of criterial particles, assumes a uniform syntactic format which transparently expresses articulations relevant for scopediscourse semantics such as operator-scope domain, topic-comment, focuspresupposition. Criterial heads and features trigger simple interpretive processes at the interfaces with sound and meaning. This approach, strongly relying on syntactic configurations, can be said to "syntacticize" scope-discourse semantics. We have briefly compared this approach with one taking the opposite direction, assuming an extremely impoverished syntax (reducing functional structures of the clause and the left periphery to a minimum, basically $\mathrm{C}$ and I), and "pragmaticising” syntax, i.e., shifting much of the computational burden to postinterface interpretive systems, not only for interpretation proper, but also for ordering in the sequence and cooccurrence restrictions. We have discussed two very simple arguments favoring the criterial approach: the existence in many languages of overt criterial heads populating the left periphery, which are hard to reanalyze as case-like or postpositions attached to the relevant phrases; and the existence of many clear cases of C-particles occurring in distinct positions with respect to other elements, and even co-occurring in distinct positions of the same left-peripheral structure.

9 I would like to thank Ian Roberts for providing and discussing the English data analyzed in this section. 
We have then turned to the "further explanations" of properties of the functional sequence through fundamental principles of linguistic computations operating within the syntactic module or at the interfaces. The search for further explanations, far from being detrimental for the cartographic study, is a crucial element of the same endeavour: the aim of arriving at further explanations of aspects of the functional sequence presupposes the detailed exploration of the cartography of syntactic structures, and can nourish it by generating new testable predictions on the functional sequence. I have illustrated the interaction between cartographic maps and further explanation by sketching out a comparative study of topicalization in English and Italian, suggesting that certain differences in the functional sequence can be traced back to the theory of locality, interpretive principles, and a primitive parametric difference between the two constructions, the fact that Italian uses clitic resumption and English has recourse to a null operator connecting the topic and the gap.

\section{Acknowledgements}

I would like to thank Enoch Aboh, Adriana Belletti, Liliane Haegeman, Clarisse Hager, Maria Lluïsa Hernanz, Richard Kayne, Rachel Nye, Jean-Yves Pollock, Ian Roberts, Ur Shlonsky for much help with data and analysis.

\section{References}

Abels, K., 2012. "The Italian Periphery: A View from Locality”, Linguistic Inquiry, 43(2).

Aboh, E., 2004. The Morphosyntax of Complement-Head Sequences: Clause Structure and Word Order Patterns in Kwa. New York: Oxford University Press.

Bassong, P.R., 2010. "The structure of the left periphery in Basaa”. Ms., University of Yaounde I, Cameroon.

Belletti, A., 2004a. "Aspects of the Low IP Area”. In The Structure of CP and IP: The Cartography of Syntactic Structures, Vol. 2, L. Rizzi (ed). New York: Oxford University Press.

Belletti, A. (ed.), 2004b. Structures and Beyond: The Cartography of Syntactic Structures, Vol. 3. New York: Oxford University Press.

Belletti, A., 2009. Structures and Strategies. London: Routledge.

Belletti, A., N. Friedmann, D. Brunato and L. Rizzi, 2012. "Does gender make a difference? Comparing the effect of gender on children's comprehension of relative clauses in Hebrew and Italian", Lingua 122(10).

Benincà, P., 2001. "The position of Topic and Focus in the left periphery", in G. Cinque \& G. Salvi (eds.) Current Studies in Italian Syntax offered to Lorenzo Renzi, North-Holland Linguistic Series, Elsevier, pp. 39-64. 
Benincà, P., 2006. "A detailed map of the left periphery of Medieval Romance”. In Crosslinguistic Research in Syntax and Semantics - Negation, Tense and Clausal Architecture, R. Zanuttini, H. Campos, E. Herburger, \& P. Portner (eds). Washington D.C: Gewogrgetown University Press.

Benincà, P. and N. Munaro (eds), 2010. Mapping the Left Periphery. The Cartography of Syntactic Structures, vol. 5. Oxford University Press, Oxford - New York.

Benincà, P. and C. Poletto, 2004. “Topic, Focus and V2: Defining the CP sublayers”. In The Structure of CP and IP: The Cartography of Syntactic Structures Vol. 2, L. Rizzi (ed). New York: Oxford University Press. 52-75.

Bianchi, V. and M. Frascarelli, 2010. “Is Topic a Root Phenomenon?” Iberia, 2(1).

Biloa, E., 2012. The Syntax of Tuki: A Cartographic Perspective, John Benjamins, Amsterdam.

Bocci, G., 2012. The Syntax-Prosody Interface: A cartographic perspective with evidence from Italian. Amsterdam: John Benjamins.

Browning, M., 1996. "CP Recursion and that- $t$ Effects", Linguistic Inquiry, 27, 237-256.

Cardinaletti, A., 2004. "Toward a Cartography of Subject Positions". In The Structure of CP and IP: The Cartography of Syntactic Structures, Vol. 2, L. Rizzi (ed). New York: Oxford University Press.

Cecchetto, C., 2000. “Doubling Structures and Reconstruction”, Probus 12, 93-126.

Cheng, L., 1997. On the Typology of Wh-Questions. Garland, New York.

Chomsky, N., 1977a. 'On Wh Movement', in A. Akmajian, P. Culicover, T. Wasow (eds.) Formal Syntax, New York: Academic Press, 71-132.

Chomsky, N., 1986. Knowledge of Language, Praeger, New York.

Chomsky, N., 1995. The Minimalist Program. Cambridge, MA: MIT Press.

Chomsky, N., 2000. "Minimalist inquiries: The framework". In Step by step: Essays on minimalist syntax in honor of Howard Lasnik, R. Martin, D. Michaels \& J. Uriagereka (eds). Cambridge, MA: MIT Press.

Chomsky, N., 2004. "Beyond Explanatory Adequacy". In Structures and Beyond: The Cartography of Syntactic Structures, Vol. 3, A. Belletti (ed). New York: Oxford University Press.

Chomsky, N., 2007. "Approaching UG from Below”. In Interfaces + Recursion = Language?, U. Sauerland and H.-M. Gärtner (eds). Berlin: Mouton de Gruyter.

Chomsky, N., 2012. "Problems of Projection", to appear in Lingua, special issue Core Ideas and Results in Syntax.

Cinque, G., 1977. “The Movement Nature of Left Dislocation”, Linguistic Inquiry 8, 297-411.

Cinque, G., 1990. Types of $A^{\prime}$-Dependencies. Cambridge, MA: MIT Press.

Cinque, G., 1999. Adverbs and Functional Heads. Oxford: Oxford University Press.

Cinque, G. \& L. Rizzi, 2010. "The Cartography of Syntactic Structures”. In The Oxford Handbook of Linguistic Analysis, B. Heine and H. Narrog (eds). New York: Oxford University Press.

Cinque, G. ed., 2002. The Structure of DP and IP: The Cartography of Syntactic Structures, Vol. 1. New York: Oxford University Press.

Craenenbroeck, J. van, 2006. Transitivity failures in the left periphery and foot-driven movement operations. 2006. J. van de Weijer \& B. Los (eds.). Linguistics in the Netherlands 2006. 52-64.

Craenenbroeck, J. van (ed), 2009. Alternatives to Cartography. Berlin: Mouton de Gruyter.

Cruschina, S., 2011. Discourse-related Features and Functional Projections. New York: Oxford University Press.

Danckaert, L., 2012. Latin Embedded Clauses: The left periphery. Amsterdam: John Benjamins. 
Durrleman, S., 2008. The Syntax of Jamaican Creole - A Cartographic Perspective. Amsterdam: John Benjamins.

Endo, Y., 2007. Locality and Information Structure - A Cartographic Approach to Japanese. Amsterdam: John Benjamins.

Franco, I., 2009. Verbs, Subjects and Stylistic Fronting, doctoral dissertation, University of Siena.

Frascarelli, M. and R. Hinterhölzl, 2007. Types of Topics in German and Italian. In S. Winkler and K. Schwabe, eds., On Information Structure, Meaning and Form. 87-116. Amsterdam: Benjamins.

Frascarelli, M. and A. Puglielli, 2010. "Focus in the Force-Fin System. Information Structure in Cushitic Languages”. In Focus Strategies: Evidence from African languages, E. Aboh, K. Hartmann and M. Zimmermann (eds). Berlin: Mouton de Gruyter.

Friedmann, N., A. Belletti and L. Rizzi, 2009. "Relativized relatives. Types of intervention in the acquisition of A-bar dependencies”, Lingua 119.

Grewendorf, G., 2002. “Left Dislocation as Movement”. In Georgetown University Working Papers in Theoretical Linguistics, S. Manck \& J. Mittelstaedt (eds), 31-81.

Hager, C., 2013. La structure de la phrase en Abidji, Doctoral dissertation, in prepararion, Unibersity of Geneva.

Harley, H., 2011. “A Minimalist Approach to Argument Structure”, in C. Boeckx (ed.), The Oxford Handbook of Linguistic Minimalism, Oxford University Press, Oxford - New York.

Haegeman, L., 1994. An Introduction to Government-Binding Theory. Oxford: Blackwell. Haegeman, L., 2012. Adverbial Clauses, Main Clause Phenomena, and Composition of the Left Periphery: The Cartography of Syntactic Structures, Volume 8. New York: Oxford University Press.

Heine, B. and T. Kuteva, 2002. World lexicon of grammaticalization. Cambridge: Cambridge University Press.

Higginbotham, J. and R. May, 1981. Questions, Quantifiers and Crossing Linguistic Review 1: 41-80.

Jayaseelan, K. A., 2008. “Topic, Focus and Adverb Positions in Clause Structure," Nanzan Linguistics, 4: 43-68.

Kayne, R., 1983. Connectedness and Binary Branching, Foris Publications, Dordrecht.

Kayne, R., 1994. The Antisymmetry of Syntax, MIT Press, Cambridge, Mass.

Kayne, R., 2005. Movement and Silence. New York: Oxford University Press.

Koopman, H. and D. Sportiche, 1982. "Variables and the Bijection Principle”, The Linguistic Review 2: 139-160.

Koster, J., 1978. Locality Principles in Syntax, Dordrecht: Foris Publications.

Krapova, I. \& G. Cinque, 2004. "On the Order of wh-phrases in Bulgarian Multiple wh fronting", ms., University of Venice.

Laenzlinger, C., 1998. Comparative Studies in Word Order Variation: Adverbs, pronouns, and clause structure in Romance and Germanic. Amsterdam: John Benjamins.

Ledgeway, A., 2004. "Il sistema completivo dei dialetti meridionali: la doppia serie di complementatori”. Rivista Italiana di Dialettologia 27.

Marantz, A., 2012. "Verbal Argument Structure: Events and Participants", Lingua, special issue Core Ideas and Results in Syntax.

McCloskey, J., 1992. “Adjunction, Selection and Embedded Verb Second”, ms., UCSC.

Mioto, C., 1999. “A periferia esquerda no português brasileiro”, ms., Universidade Federal de Santa Catarina, University of Siena. 
Munaro, N. and J.-Y. Pollock, 2005. “Qu'est-ce que (qu)-est-ce que? A Case Study in Comparative Romance Interrogative Syntax”, in G. Cinque \& R. Kayne (eds), Handbook of Comparative Syntax. New York: Oxford University Press, 542-606.

Nakajima, H., 1992. "The Split-Comp Hypothesis and the Whether-If Alternation”, ms., Tokyo Metropolitan University.

Obenauer, H., 1983. “On the Identification of Empty Categories”, Linguistic Review 4, 153-202.

Obenauer, H.-G. and C. Poletto, 2000. "Rethorical wh-phrases in the left periphery of the sentence", University of Venice Working papers in Linguistics, 19(1), 121.151.

Paoli, S., 2007. "The fine structure of the left periphery: COMPs and subjects; evidence from Romance”. Lingua, 117:6.

Paul, W., 2005. "Low IP area and left periphery in Mandarin Chinese". Recherches linguistiques de Vincennes 33.

Pearce, Elizabeth, 1999. “Topic and Focus in a head-initial language: Maori," Proceedings of AFLA vi. The Sixth Meeting of the Austronesian Formal Linguistics Association, held at the University of Toronto April 16-18, 1999, edited by Carolyn Smallwood and Catherine Kitto, pp. 249-263. University of Toronto Working Papers in Linguistics.

Plann, S., 1982. “Indirect Questions in Spanish,” Linguistic Inquiry 13: 297-312.

Poletto, C., 2000. The Higher Functional Field. Evidence from Northern Italian Dialects. New York: Oxford University Press.

Poletto, C., and J.-Y. Pollock, 2004. "On Wh-clitics, Wh-doubling in French and some North Eastern Italian Dialects”, Probus, 16.2, 2004, 241-272.

Pollock, J.-Y., 1989. “Verb Movement, Universal Grammar and the Structure of IP”, Linguistic Inquiry 20: 365-424.

Puskás, G., 2000. Word Order in Hungarian: The syntax of Ā-positions. Amsterdam: John Benjamins.

Ramchand, G., 2008. Verb Meaning and the Lexicon, Cambridge University Press, Cambridge.

Rizzi, L., 1982. Issues in Italian Syntax. Dordrecht, Foris Publications.

Rizzi, L., 1990. Relativized Minimality. Cambridge, MA: MIT Press.

Rizzi, L., 1991. "Residual Verb Second and the Wh Criterion”, Geneva Working Papers on Formal and Computational Linguistics, republished in Rizzi (2000).

Rizzi, L., 1997. “The Fine Structure of the Left Periphery”. In Elements of Grammar, L. Haegeman (ed), Kluwer, Dordrecht.

Rizzi, L., 2000. Comparative Syntax and Language Acquisition, Routledge, London.

Rizzi, L., 2001. "On the Position Int(errogative) in the Left Periphery of the Clause”. In Current Studies in Italian Syntax Offered to Lorenzo Renzi, G. Cinque and G. Salvi (eds). Amsterdam: Elsevier.

Rizzi, L., 2004a. Locality and Left Periphery. In Structures and Beyond. The Cartography of Syntactic Structures, vol. 3, A. Belletti (ed). New York: Oxford University Press.

Rizzi, L. (ed.), 2004b. The Structure of CP and IP - The Cartography of Syntactic Structures, vol. 3, OUP.

Rizzi, L., 2006. “On the Form of Chains: Criterial Positions and ECP Effects”. In On Wh Movement, L. Cheng, N. Corver (eds). MIT Press, Cambridge, Mass.

Rizzi, L., 2010. “Some Consequences of Criterial Freezing”, Festschrift for Tarald Taraldsen, edited by P. Svenonius, Oxford University Press.

Rizzi, L. \& I. Roberts, 1989. “Complex Inversion in French”, Probus 1, 1-30.

Rizzi, L. and U. Shlonsky, 2007. "Strategies of Subject Extractioin". In Interfaces + Recursion = Language?, U. Sauerland and H.-M. Gärtner (eds). Berlin: Mouton de Gruyter. 
Roberts, I., 2004. “The C-system in Brythonic Celtic Languages, V2 and the EPP”. In Rizzi, ed. 2004b.

Roberts, I., 2012. "Diachrony and Cartography: Paths of Grammaticalization and the Clausal Hierarchy", ms., Downing College, Cambridge.

Roberts, I. and A. Roussou, 2003. Syntactic Change : A Minimalist Approach to Grammaticalisation. Cambridge: Cambridge University Press, 2003.

Ross, J.R., 1967. Constraints on Variables in Syntax. PhD dissertation, MIT, Cambridge, MA.

Saito, M., 2010. "Sentence Types and the Japanese Right Periphery". Ms., Nanzan University, Nagoya.

Salvi, G., 2005. "Some Firm Points on Latin Word Order: The Left Periphery”, in K. E. Kiss, ed., Universal Grammar and the Reconstruction of Ancient Languages, Mouton de Gruyter, Berlin.

Shlonsky, U., 2000. "Subject Positions and Copular Constructions". In Interface strategies, H. Bennis, M. Everaert and E. Reuland (eds). Amsterdam: Royal Netherlands Academy of Arts and Sciences.

Shlonsky, U., 2010. “The Cartographic Enterprise in Syntax”. Language and Linguistics Compass 4(6).

Shlonsky, U. and G. Soare, 2011. "Where's why”, Linguistic Inquiry 42, 651-669.

Speas, P. and C. Tenny, 2003. “Configurational Properties of Point of View Roles”. In Asymmetry in Grammar, DiSciullo, A. M. (ed). Amsterdam: John Benjamins.

Starke, M., 2001. Merge Dissolves into Move, Doctoral Dissertation, University of Geneva.

Starke, M., 2009. "Nanosyntax: a short primer to a new approach to language". Nordlyd 36(1).

Suñer, M., 1994. "V-movement and the Licensing of Argumental Wh Phrases in Spanish", Natural Language and Linguistic Theory, 12, 335-372.

Torrence, H., 2012. The Clause Structure of Wolof: insights into the left periphery. Amsterdam: John Benjamins.

Tsai, D., 2008. "Left Periphery and Why-How Alternations". Journal of East Asian Linguistics $17(2)$.

Zanuttini, R. and P. Portner, 2003. "Exclamative Clauses: At the Syntax-Semantics Interface”. Language 79(1). 